Endocrinol. Japon., Vol. 4, No. 4 (1957)

\title{
PARAFOLLIGULAR CELL IN THE RAT THYROID
}

\author{
KOICHI SAITO AND KATSUHIRO SHIBATA
}

\author{
Department of Pharmacology and Endocrinological Laboratories, \\ School of Medicine, Gunma University, Maebashi
}

So far as the authors are aware, the first description of the parafollicular cell (PC) in the thyroid was made by Nonidez (1932) with the dog. In the same year, Raymond (1932) reported the occurrence of the cell in the rabbit thyroid too. More recently, some contributions were rendered to its morphology (Sugiyama, 1954 ; Sandritter et al., 1956), but in the present knowledge detailed informations as to the nature of the cell in question are still lacking. One of the authors, Saito (1956), has explored the cell in various kinds of vertebrates and found its universal occurrence excepting in teleosts such as the catfish, Parasilurus. In the present experiments, age and sex differences in PC (Exp. 1), relation between PC and the pituitary-thyroid system (Exp. 2) and responses of PC to some chemical and physical conditionings (Exp. 3) were investigated with the rat thyroid.

\section{MATERIALS AND METHODS}

Male and female rats of the Wistar strain were used. In Exp. 1, 36 animals were divided into 6 age groups, viz., 1, 7, 21, 30, 40 and 80 days, each group consisting of 3 males and 3 females. In Exp. 2, 57 adult females were divided into the following 5 groups: Group 1 (control) consisted of 6 subgroups of each 2 rats of the same age and of approximately the same weight as those of subgroups corresponding to those of group 2 ; group 2 (hypophysectomized at 50 days after birth) contained 30 in total, and were divided into 6 subgroups according to postoperative weeks $-1,2,3,8,13$ and 16 weeks after the hypophysectomy, each consisting of 5 animals; group 3 (methylthiouracil-treated) consisted of 5 rats, on whose backs each $125 \mathrm{mg}$ of methylthiouracil (Methiosil, Chugai Pharm. Co.) was embedded intramuscularly 2 weeks before investigation; group 4 (thyroxine-injected) consisted of 5 which were subcutaneously injected once daily with $0.1 \mathrm{mg}$ of thyroxine (Squibb) for 5 days, the last injection being made 24 hours before investigation; and group 5 (TSH-treated) consisted of 5 which were once intraperitoneally injected with $1.0 \mathrm{mg}$ of thyrotropin (Armour) 24 hours before investigation. In Exp. 3, 35 adult female rats were divided into the following 7 groups of 5 each: Group 1 (control) - each subcutaneously injected with $0.5 \mathrm{cc}$ of saline; group 2 (pilocarpin-injected) each subcutaneously injected once with $16 \mathrm{mg}$ of pilocarpin hydrochloride (Shionogi Pharm. Co.) 5 hours before investigation; group 3 (atropin-injected) - each subcutaneously injected once with $70 \mathrm{mg}$ of atropin sulfate (Torii Co.) 5 hours before investigation; group 4 (adrenalin-injected) - each subcutaneously injected once with $150 \mu \mathrm{g}$ of adrenalin hydrochloride (Daiichi Pharm. Co.) 2 hours before investigation; groups 5 (high temperature) and 6 (low temperature)-kept for 24 hours in incubators maintained at $35^{\circ}$ and $5{ }^{\circ} \mathrm{C}$, respectively; and group 7 (trypan blueinjected) - each subcutaneously injected with $1 \mathrm{cc}$ of $1 \%$ trypan blue (Merck) solution for 5

Received for publication September 20, 1957. 
consective days, the last injection being completed 24 hours before investigation. Animals were weaned from the breast on the 21 st day, and thereafter fed on a commercial laboratory chow (Oriental \& Co.) and given appropriate amount of drinking water.

The specimens were prepared in the following way: The thyroid gland removed immediately after the sacrifice was fixed with Levi's or Zenkel-formol solutions, and after the routine paraffin technic, cut in $3 \mu$ serial sections. Specimens from the trypan blue group were fixed with Susa. Sections were stained with periodic acid Schiff's reaction (PAS), iron hematoxylin (Heidenhain), hematoxylin-eosin, Azan, Kull, Weigert and van-Gieson.

\section{RESULTS}

\section{Exp. 1. Age and sex differences in $P C$}

In the 1 day and the 7 day age groups, follicles in the thyroid were not sufficiently developed, and neither PG nor cells differentiated in the final embryonal stage were observed. In the 21 day age group, two types of PG were evidently visible: The one was represented by the so-called clear cells with nearly round or polygonal forms larger than epithelial cells. The cells were stained light grey with iron hematoxylin, light purple with Azan, and generally stained lighter than epithelial cells. Rod- or thread-shaped mitochondria were observed in indefinite arrangement. The nuclei were nearly round and large, found approximately in the center of the cell body, and poor in chromatin. Nucleolei numbered 3-4 in each cell. The clear cells were found in most cases, being inserted between the basement and basement membrane of $2 \sim 3$ epithelial cells, singly or in aggregation of several, and sometimes in several places of one follicle. Sometimes they were in direct contact with the colloid, but in most cases separated from the latter by epithelial cells (Fig. 1). Sometimes they were observed proliferated to form a stroma pressing the basement membrane in the shape of a bud or nodule. In such cases, the boundaries between cell bodies were indistinct, mitosis being seen occasionally. These clear cells were found at the center of the thyroid gland in general. Another type of PG was represented by the so-called granular cells including particular granules. Their properties resembled those of the clear cells. The granules stained deep purple with PAS, and black purple with iron hematoxylin. They tended to be close to the cell membrane. Some of these cells contained vacuoles (Fig. 2). The granular cells were sometimes found in aggregation, which, owing to proliferation, penetrated from the follicular epithelium into the stroma in the forma of a nodule. The clear cells were more numerous than the granular ones in general. In the 30 day, 40 day and 80 day groups, PG tended to be increased.

In all ages in the present animals, no sex difference was obserbed with respect to the morphology of $\mathrm{PC}$.

Exp. 2. Relationship between $P C$ and pituitary-thyroid system

a) Hypophysectomized group: In the 1-postoperative week group, follicles in the central part were generally smaller, and those in the peripheral part larger and irregularly round-shaped. Epithelial cells were flat with indistinct boundaries, and the cytoplasm stained purple with Azan. No secretory granules, secretory vacuoles and abnormal granules were observed. Nuclei were spindle-shaped and deep stainable. The colloid was stained red orange with Azan and uniformly 


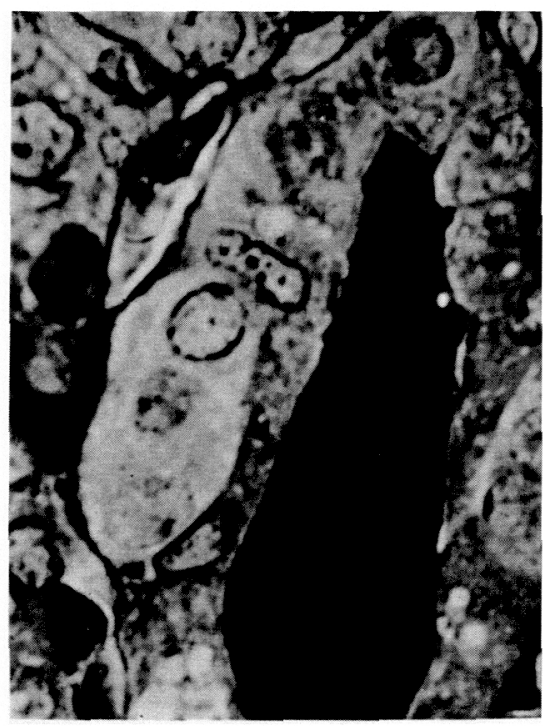

Fig. 1. Clear cells in the intact rat, being insterted between the basement and basement membrane of epithelial cells.

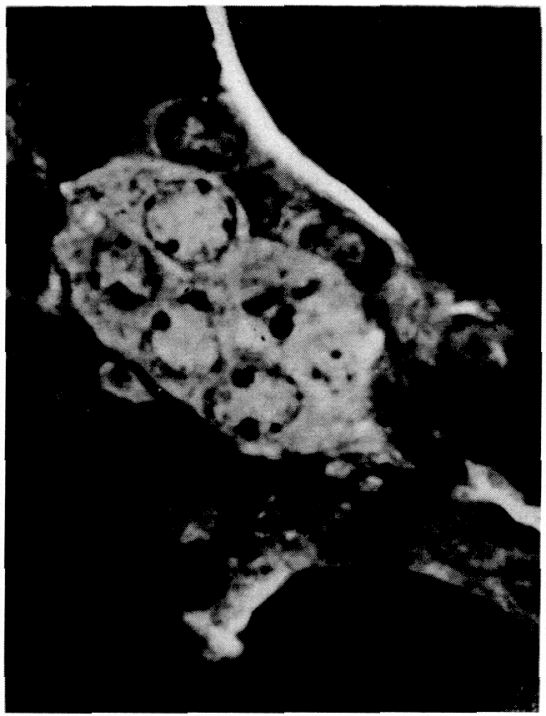

Fig. 3. Clear cells in the 1-postoperative week rat, bulging outward the basement membrane.

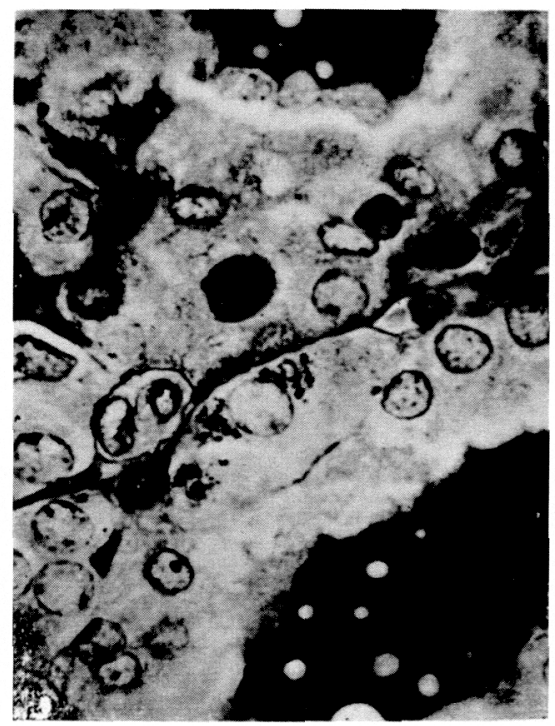

Fig. 2. Granular cell in the intact rat.

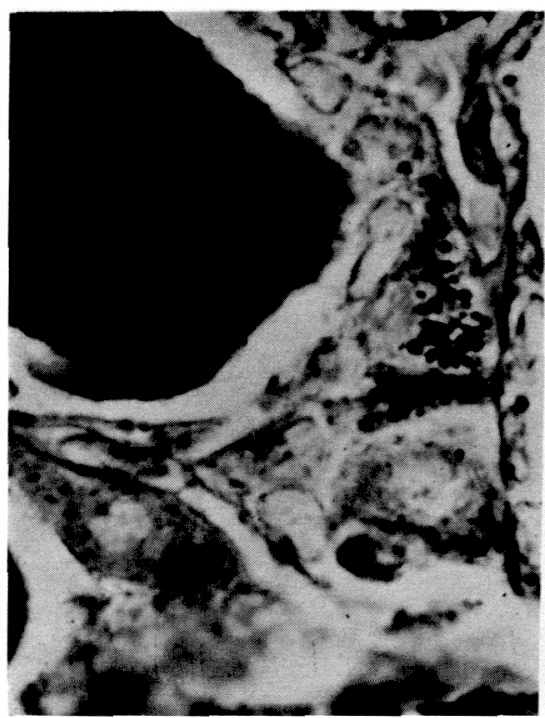

Fig. 4. Granular cells in the 1-postoperative week rat. 


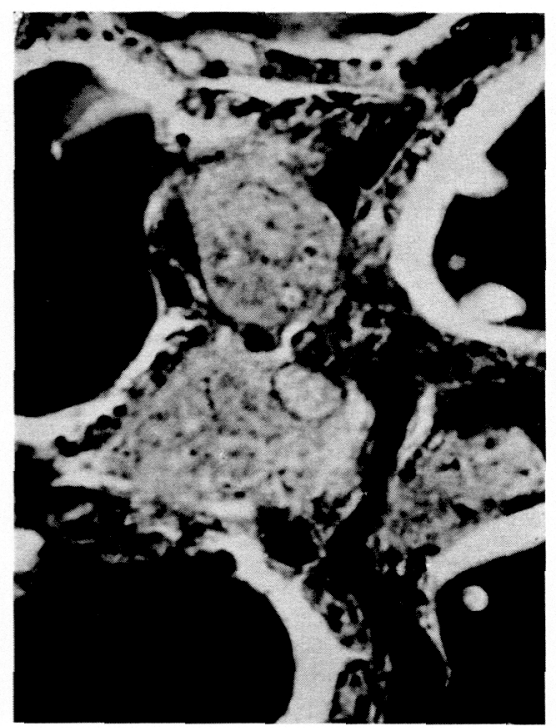

Fig. 5. Clear cells in the 8-postoperative week rat.

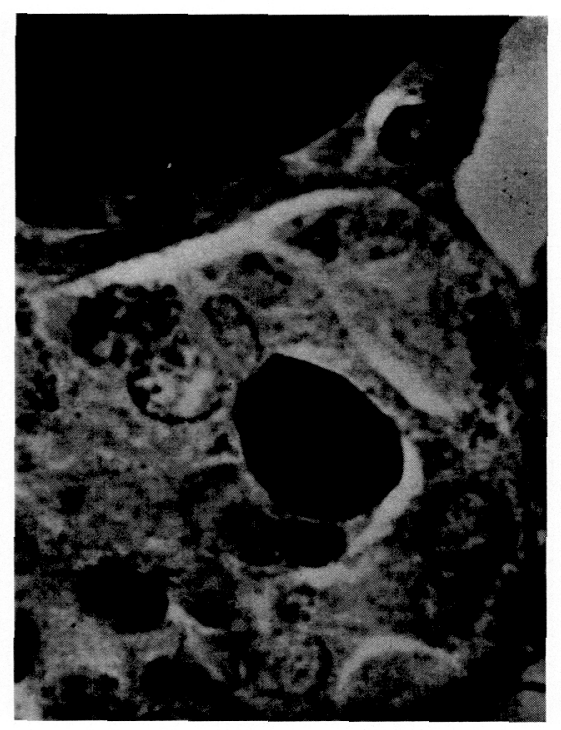

Fig. 7. Clear cells in the thyroxine injected rat.

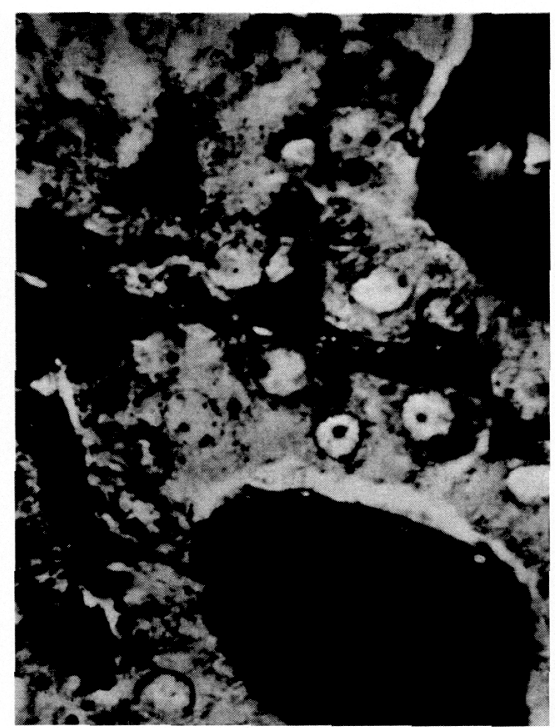

Fig. 6. Granular cells in the methylthiouracil injected rat.

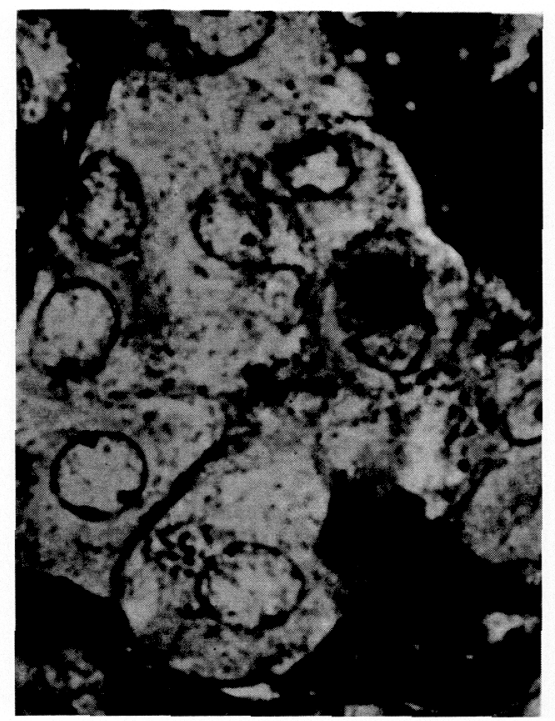

Fig. 8. Clear and granular cells in the TSH injected rat. 
deep with both PAS and iron hematoxylin. No peripheral vacuoles could be seen. Large clear cells were seen inserted between epithelial cells or bulging outward the basement membrane (Fig. 3). In contrast with atrophic epithelial cells, the clear cells were large and their nuclei almost rounded, large and pale. There were granular cells containing minute granules which were strongly PASpositive, showing marked affinity to iron hematoxylin (Fig. 4). The findings with the 2-postoperative week group were nearly the same as with the 1-postoperative week group. In the 3-postoperative week group, the variation in the size and irregularity in the form of follicles was remarkable, and especially in the pcripheral part, large and irregular-formed masscs which seemed to be produced by the fusion of follicles were prominent. Follicular epithelium, still more atrophied, could be noted only as bulges of nuclei on the basement membrane, showing the characters of the endothelium. This seemed to be the stage in which the effect of hypophysectomy was most remarkable, notwithstanding that no noticeable change in PC was the case. In the 8-postoperative week group, the findings in the peripheral part resembled those in the 1-, 2- and 3-postoperative week groups, but in the central part, many clear cells surrounded follicles, or protruded in the form of a nodule (Fig. 5). In the 13- and 16-postoperative week groups, follicles were nearly round and small in general. Epithelial cells were atrophic, though to a lesser degree than in the above mentioned earlier operated groups. Furthermore the clear and granullar cells were distinctly observed.

b) Methylthiouracil group: Follicles were irregular in form and variable in size. Follicular epithelium assumed high cylindrical form and in it, rod- or long thread-shaped mitochondria stained with iron hematoxylin, were arranged regularly in parallel with the long axes of the epithelial cells. They were in particular distinctly seen in the form of small granules in the functional poles. The nuclei were large in size, localized toward the basement, nucleoli increased, and many mitotic figures were visible, but without signs of secretory activity. PC were found between the basement and the basement membrane of epithelial cells. Many minute PAS-positive granules were observed in some parts (Fig. 6). But the clear cells were often hard to distinguish because of their resemblance to the epithelium.

c) Thyroxine group: Follicles were varied in size and generally irregular in form. Such was especially notable in the peripheral part. Epithelial cells were cuboid- or flat-shaped, and deep stainable in general. Mitochondria, irregular in form, were observed only in a small number in the surroundings of nuclei, which were spindle-shaped and deep stainable. There were no peripheral vacuoles. In this way, the epithelium was atrophic, but PG were found adjacent to the colloid or continuous with the basement of follicles pressing the stroma. PG became more evident when epithelial cells were atrophic (Fig. 7).

d) TSH group: Details are omitted since they were already reported by the authors (Shibata et al. 1955). The findings were very similar to those of the methylthiouracil group, except that PC were evidently distinguished from the epithelial cells (Fig. 8).

Exp. 3. Response of PC to some chemical and physical conditionings 
In the pilocarpin, the atropin and the adrenalin groups as well as the high and the low temperature groups there were no remarkable changes in PC. As regards the epithelial cells of the trypan blue group, they were scarcely different from the control except that in the stroma of the former, cells which took up trypan blue were scatteredly visible. These phagocytes were swollen to nearly round shape with eccentric nuclei, and trypan blue was traceable as minute granules or diffusely in the cell body. On the other hand, reticulo-endothelial cells and periarteriolal cells were remarkably swollen, and many of them tended to be freed. It was demonstrated that the uptake of trypan blue was confined to reticulo-endothelial cells and no trypan blue was found in PC.

\section{DICUSSION}

According to Nonidez (1932) who introduced the term "Parafollicular cell", the cell appeared first in the epithelium of the follicie, and then moved gradually among follicles, forming a cluster-like cell aggeregation. Sugiyama (1954) classified PC closely associated with blood capillaries into clear and dark cells in the guinea pig thyroid. Ohida (1954) reported that there was no significant change in PC in the thyroid of the castrated mouse, Sawasaki (1955) observed increased PC in the rabbit thyroid in the early and middle perind of pregnancy, and Kano (1952) failed to observe any in the human thyroid.

As regards the significance of $\mathrm{PC}$, the following hypotheses can be made from reports hitherto published: (1) The cell would participate in the contraction and relaxation of the follicle in relation to the storage and discharge of the colloid; (2) it would participate in the destruction of the follicle; (3) it might represent some vestiges of embryonic structures; (4) it would participate in the formation of new follicle; (5) it would be a part of the follicular wall which appears in a particular section of the follicle; (6) it would only show up a phase of reabsorption process of the epithelial cell; (7) it would be a cell under the control of the autonomic nerve; (8) it would be endocrine cell which has no relation with the hitherto known thyroid functions; and (9) it would be a kind of reticulo-endothelial cell playing an intermediate role in the uptake of the intrafollicular colloid and the discharge of it into the blood capillaries or lymph spaces.

In the observation of the age difference in PC in the present experiment, it was demonstrated that there was a distinction between the clear and dark cells, and that they formed cell aggregations. Therefore, they cannot be considered to play the part of basket cells such as in the parotid gland, and subsequently hypothesis (1) would be denied.

Hypothesis (2) that PG, freed from the follicular wall, would destroy the follicle causing the discharge of colloid into the stroma and then into circulation would also be denied, since no direct evidence for it was demonstrated.

Hypothesis (3) that PG are differentiated from embryonic particular cells or they are only vestiges of embryonic structures would be denied on account of lack of evidence indicating the appearance of $\mathrm{PG}$ in the embryonic stage.

Hypothesis (4) that PC participate in the formation of new follicles has recently been advanced by Scharf and his co-workers (1954 a,b, 1955), who stated 
that the control of the multiplication of thyroid follicles, of which no explanation has hitherto been made, would probably be made by daughter cells from follicular epithelium surrounding the follicle, and later forming cell aggregation. In the present experiments, it was found that PG increased in number with age and that they were found in the central part of the thyroid. Subsequently it was assumed that in the clear cells from follicular epithelium, thickening and separation of mitochondria would occur, followed by the formation of many granules (granular cells), resulting into secretory vacuoles, granular cells would discharge colloid into the intercellular space, and from its storage new follicles would be formed. Namely, the results of the present experiments seems to support hypothesis (4).

There are many reports concerning the thyroid of the hypophysectomized rat, and the findings in the present experiments were nearly in conformity with them, though considerable variations were observed depending on the postoperative period. The effect began to appear in 1 postoperative week, and was most evidently manifested in 3 postoperative weeks. In 8 postoperative weeks, the clear cells were found increased in atrophied follicular epithelium and between this and the basement membrane. Sometimes they surrounded the follicular epithelium, and sometimes they protruded into the stroma in the form of a nodule. In 13 and 16 postoperative weeks; each follicle was generally small but the same in size and regular in shape, presenting a stable aspect in the whole. This indicates the recovery of the follicle by the clear cell which appeared more evidently after about 8 postoperative weeks. This also supports hypothesis (4).

Concerning change in PG after hypophysectomy, or in response to administration of methylthiouracil, thyroxine or $\mathrm{TSH}$, no concrete information has yet been available. The result in the present experiments showed that PC have no direct relationship with the pituitary-thyroid system. And that parallel change was not produced in follicular epithelium and PC through administration of the above mentioncd drugs wculd deny hypothesis (5) that PC would be a part of follicular epithelium which has been regarded as some particular objects owing to a certain manner of section in the preparation of the specimens.

De Robertis (1\$42, 1050) and Dvoskin (1948) stated that the colloid secreted into the follicular space wculd again be taken up the process or the pseudopod at the end of the cpithelium, and released into the capillary or the lymph space frcm its bastment. If so, epithelial cells which had reabsorbed colloid might be observed as granular cells. But as already reported by the present authors (Shibata et al., 1955), the assumption of the reabsorption by the follicular epithelium has no cytolcgical grcund and it seems certain that they, like general excretory cells, only perform one directional excretion into the space. This denies hypothesis (6).

It has long been suspected that the thyroid is under control of the nervous system, especially of the autonomic one. Especially the relation between PC and the autonomic nervous system was emphasized by Sandritter et al. (1955) on the ground of histochemical investigation. In the present experiments, however, autonomic drugs in the doses used did not produce any significant changes in the frequency of occurrence, the distribution or the properties of $\mathrm{PG}$. 
Mansfeld (1940) separated from the thyroid gland "Thermothyrin" bearing on the biochemical thermoregulating mechanism and which is antagonistic to thyroxine. It may be suspected that this substance might be produced by PG. In the present experiments, rats were exposed to high and low temperatures but no particular change was induced in $\mathrm{PG}$ in parallel with that in the epithelial cells. These results would deny hypothesis (8).

Tabe and Wakabayashi (1940) reported the presence of phagocytes in the human thyroid, and Goble (1954) demonstrated in thyroid of a dog infected by Trypanosoma cruzi, spherical agranular cells with eccentric nuclei. Boyd (1942) noted macrophages which sometimes occur in the acini in nodular goiter, and Hellwig (1951) colloidophagy stimulated by excess of thyrotropic hormone. Thus, there are many reports on the presence of reticulo-endothelial cells which are designed, apart from follicular epithelium, only to take up the colloid, and whose position and morphology are extremely similar to those of PC. In the present experiments, reticulo-endothelial cells in the whole body were remarkably swollen, proliferated, and the uptake of the administered trypan blue was the same as described in the preceding works. In the thyroid, however, only reticulo-endothelial cells in the stroma had remarkably taken up trypan blue, but none was observed in PC. From this fact it is clear that PG can not be taken as reticuloendothelial cells as understood by the past conception, and hence hypothesis (9) is denied.

From these results, it may be inferred that PC are cells which participate in the production of new follicles.

\section{SUMMARY}

Experiments were carried out on the parafollicular cells (PC) in the rat thyroid, with the following results.

These are independent cells which develop from follicular epithelium at 3 weeks of age, increasing with age. They can be divided into the clear and granular cells, and the transformation from one type to the other is noted. PC are independent from the changes produced in follicular epithelium by the administration of TSH, methylthiouracil or thyroxine.

PC are visible at long time after the hypophysectomy, becoming rather more distinct with the lapse of time: Any observable change was not induced by the administration of autnomic drugs nor by exposure to high or low temperature. PG did not take trypan blue in an attempt of vital staining.

From these results PC are considered to participate in the production of new follicles.

\section{ACKNOWLEDGMENTS}

The authors are indebted to Dr. Sanford L. Steelman, Armour Laboratories, Chicago, Ill. (present adress: Baylor University, Houston, Texas), for the kindness in supplying TSH and to Dr. O. Wintersteiner, Squibb Institute for Medical Research, New Brunswick, N.J., U.S.A., for the generous gift of thyroxine. 


\section{REFERENGES}

Boyd, W. (1942). Surgical Pathology, Ed. 5, W. B. Saunders Co., Philadelphia. p. 189. De Robertis, E. (1942). Anat. Rec. 84, 125.

De Robertis, E. (1950). General Cytolgoy, W. B. Saunders Co., Philadelphia. p. 306.

Dvoskin, S. (1948). Endocrinol. 43, 52.

Goble, F.S. (1954). Am. J. Path. 30, 599.

Hellwig, C. A. (1951). Science 113, 725.

Kano, K. (1952). Arch. hist. jap. 4, 245.

Mansfeld, G. (1940). Arch. exper. Path. u. Pharmakol. 196, 598.

Nonidez, J. E. (1932). Anat. Rcc. 53, 339.

Ohida, S. (1954). Okajima's Folia Anat. Japon. 26, 347.

Raymond, N. (1932). Anat. Rec. 53, 355.

Saito, K. (1956). Kitakanto Med. J. 6, 511. (In Japanese)

Sandritter, W., E. Kummer, G. Fillat and L. Röwe (1956). Klin. Wchnschr. 34, 871.

Sawasaki, Y. (1955). Okajima's Folia Anat. Japon. 27, 269.

Scharf, J-H. (1954 a). Verhandl. anat. Gesellsch. 52, 336.

Scharf, J-H., W. Förster, G. Herrmann and F. Ehrenbrand (1954 b). Naturwissensch. $41,406$.

Scharf, J-H. (1955). Acta neuroveg. 11, 100.

Schibata, K., E. Ogawa and K. Saito (1955). Endocrinol. Japon. 2, 23.

Sugiyama, S. (1954). Anat. Rec. 120, 363.

Tabe, H. and M. Wakabayashi (1942). Tr. Soc. Path. Jap. 30, 213. 